\title{
Urban Regeneration, Digital Development Strategies and the Knowledge Economy: Manchester Case Study
}

\author{
Dave Carter
}

Received: 9 January 2012 / Accepted: 12 January 2012 /

Published online: 10 February 2012

(C) Her Majesty the Queen in Right of United Kingdom 2012

\begin{abstract}
In the late twentieth century, cities like Manchester, seen as the 'original, modern' [1] world industrial city, faced serious challenges in terms of how to respond to the massive economic restructuring that was taking place. On the one hand, Manchester needed to respond to the highest rates of unemployment and social exclusion seen for more than 50 years, whilst, at the same time, the city wanted to develop innovative and practical solutions which could bring real economic and social benefits to local people. The impact of even more rapid technological change, referred to as the emerging 'information society', which started to impact from the 1980s onwards, exacerbated this dilemma, accelerating the process of restructuring so that within urban areas new economic growth increasingly sat side by side with extremes of poverty, unemployment and other forms of social exclusion. This case study looks at the ways that Manchester, and key players from the city region, including the public sector, business, education and the community sector, responded to this and how those responses over the past $25+$ years created new ambitions and aspirations for the city and its citizens. The conclusions focus on the concept of the 'Smart City' and Manchester's ideas on creating a more inclusive, creative and sustainable city, including through the imaginative use of digital technologies, applications and services, and a commitment to open innovation and the co-production of new and innovative services.
\end{abstract}

Keywords Smart cities · Inclusion · Creativity - Sustainable city - Open innovation · Co-production

\section{Innovation in Regeneration: A Proactive Approach to Economic and Social Change}

In the mid-1980s, the Manchester City Council embarked on a radical new approach to regeneration. A new Economic Development Department was established and

D. Carter $(\bowtie)$

Manchester Digital Development Agency, Manchester, UK

e-mail: D.Carter@manchesterdda.com 
work was commissioned to bring together people with new and innovative ideas, from research bodies, business, trade unions, the voluntary sector and the wider community, to advise the City Council leadership on how to tackle economic restructuring and the consequent impacts which were resulting in massive levels of unemployment, poverty and alienation. Out of those discussions, which also included many 'heated debates' on priorities, a number of practical proposals emerged in the late 1980s (1987-1989), including:

- There should be more of a focus on area- and neighbourhood-based working, devolving intervention to local areas and encouraging cross-sector working where the public sector would work on a more proactive basis with local communities, businesses and other public sector bodies, e.g. health.

- The idea of a 'creative city' emerged, demonstrating the economic importance of the 'arts and cultural industries', such as the idea that Manchester should look to cities such as Amsterdam and Barcelona as'24 Hour Cities' for inspiration and practical ideas for new initiatives.

- Innovation being identified as another key theme, acknowledging the lack of a coherent collaboration strategy with higher education in particular and the need to address this with some practical initiatives such as the development of Manchester Science Park (MSP) and the recognition that information and communications technologies (ICTs) could play a significant role in creating new infrastructures and services and, consequently, future economic growth.

These three themes were at the heart of the new Economic Development Strategy for the city and provided the foundation for the City Council's new 'Economic Initiatives Group' focusing on local (neighbourhood-focused) action, creative industries, and technology and innovation. They are still at the core of Manchester's neighbourhood regeneration strategy 20 years later, underpinning the two core objectives of the City Council, namely generating sustainable economic growth and reducing dependency through tackling worklessness, inequalities and social exclusion.

In 2011, the launch of the EU's Digital Agenda for Europe [2] provides a highlevel strategic framework for supporting the development of "a flourishing digital economy by 2020 "...through..."policies and actions to maximise the benefit of the Digital Revolution for all". As part of this, local action is being encouraged so that cities and regions produce 'local digital agendas' to set out their aspirations for change whilst at the same time focusing on practical action and initiatives which will deliver that change supported by user-driven open innovation through the use of digital technologies.

This comes at a time when Manchester is reviewing its own 'Digital Strategy', originally produced in 2008, and its current digital development priorities focusing on three main issues:

- Digital inclusion: continuing to tackle the 'digital divide' because, even though people generally have increasing access to the Internet and digital services, inequalities persist with large sections of excluded communities no longer having or using copper-based landlines (over $50 \%$ of households in some parts of Manchester) and, consequently, having limited or no access to the 'digital world' and where access to skills and jobs in the digital economy is still a very real challenge 
- Digital industries: building on Manchester's strengths as the largest and most dynamic cluster of digital and creative businesses outside of London to support further sector-based growth, particularly through the independent Manchester Digital trade association (www.manchesterdigital.com); finding ways to overcome barriers to growth, such as the lack of business finance to support new investment and start-ups; and the need for better access to skills and pathways to employment in the sector

- Digital innovation: generating investment for innovation and new infrastructures and working with the research community on Future Internet development to support Manchester as a 'Smart City' in areas such as smart energy, cloud computing and very high-speed next-generation access (NGA) digital infrastructures (fibre and wireless), networks and services

This review is starting with the production of a Green Paper, entitled "Smart Cities: Creating an Inclusive and Sustainable Knowledge Society: A Local Digital Agenda for Manchester", the first draft of which was produced for consultation in November 2011. This was the result of 6 months work in consulting with local stakeholders and partners, following a workshop organised by Manchester Knowledge Capital and the Manchester Digital Development Agency (MDDA) in March 2011, together with a range of discussion held with partners in the EUROCITIES Knowledge Society Forum-KSF (www.eurocities.eu), European Smart Cities projects and the European Network of Living Labs_ENoLL (www.openlivinglabs.eu). Following a further 3 months consultation period with stakeholders and partners, local, nationally and internationally, the Local Digital Agenda for Manchester is being published in Spring 2012. It will outline priorities and an action plan for realising a digitally enabled and empowered Smart City, both in the short term and to 2020 and beyond.

\section{Driving Change in Manchester: From Telematics to a New Digital Agenda}

Manchester's Experiences in Urban Regeneration and Digital Development over More Than 25 Years

In the late 1980s, when the city's new Economic Development Department was formulating its priorities for action to drive economic change, technology was largely seen as something that was neutral and passive, a product of economic change rather than a catalyst for that change. ICTs, or telematics (the convergence of telephony and informatics), were not particularly seen as being central or even that important to economic growth. There were examples in other parts of Europe, however, as well as in North America, where the power of micro-computing was being linked together with the 'plain old telephone system' to create the first open networks that were more widely available outside of universities, the wider research community and the military.

Manchester was particularly influenced by developments in Scandinavia and Germany, where 'X25' networks were providing the first open-access e-mail and conferencing systems, such as the 'GeoNet' system in Germany with its e-mail, fax and telex gateway in the UK, and the Electronic Village Halls in Denmark and 
Sweden taking ICTs out to local communities to support rural development and with links to one specific community project in the UK, the Notting Hill Information Technology Education Centre. Manchester commissioned research from the Centre for Employment Research (CER) at Manchester Polytechnic (now Manchester Met University) to review these developments and to make recommendations about how such developments could be used to support economic development and social inclusion in Manchester.

In spite of some advice the CER received, such as that 'there would be no commercial access to the Internet for at least 10 years' - this was in 1989- the report was very positive, and Manchester embarked on a proactive strategy of encouraging some of the pioneers of this early use of 'telematics' to bring their skills and infrastructure to Manchester. This resulted in the move of Poptel (the UK's first worker cooperative Internet Service Provider), working in partnership with GeoNet, to Manchester with the 'Manchester Host' computer communications and information system. The Manchester Host was launched in 1991, the UK's first locally based, globally accessible public access system offering e-mail, bulletin boards and online databases, focusing heavily on community-based users and information providers, as well as working with business and the public sector. In this way, the early roots of digital development in Manchester were as much the result of grass roots initiatives as the City Council's strategic commitments.

A network of Electronic Village Halls was set up in local neighbourhoods in Manchester in 1992, providing access to ICTs and (pre Web) Internet services, and Manchester City Council was one of the first UK local authorities to have a web site in 1993. In 1994, a new community-based organisation was established, the Manchester Community Information Network, to support capacity building work in local areas and with the voluntary and community sector (NGOs) generally, enabling them to produce electronic content and to make that accessible via the Web and associated online networks. At the same time, MSP became the home of the first 'Internet Exchange' outside of London, still the only facility of this scale and capacity outside of London, and this is a key asset in Manchester's continuing development as a digital city.

\section{Consolidating Manchester's Digital Capacities in the Twenty-First Century}

As Manchester considers its priorities for the coming period, taking into account the potential impact of the third generation of Internet development, the 'Future Internet' based on innovations around 'cloud' computing, the 'Internet of Things', open data and the 'semantic web' [3], local experience to date has created a firm foundation for future work. A recent report commissioned by the MDDA [4] to review Manchester's 'Internet Hub' capacity states:

That such an open infrastructure approach works for Manchester is evident in the history of the digital sector and the process that led to Manchester becoming the foremost Internet hub in the UK outside of London. Manchester attracted some of the earliest Internet service providers who saw potential in strong local market awareness - to some extent the result of public sector intervention. Those ISPs created a market for Internet transit and hosting services that 
attracted investment by carriers and led to the creation of hosting businesses like Telecity, a hugely successful Manchester start-up. The same ISPs spawned a growing number of web design and software businesses that took advantage of the new market opportunities. Those in turn increased further the demand for hosting and transit capacity, and the city council joined others in promoting an initiative to establish MaNAP, the first significant Internet exchange outside London. The peering activity around MaNAP and the increasing number of carriers who chose facilities in the Science Park as their point of presence led to falling Internet transit costs. This increased the attractions of Manchester as a centre for digital businesses, increasing demand for hosting, and so on in a virtuous growth spiral.

Three factors were critical in bringing this about:

- The role played by SMEs as innovators and market creators, and their need for open infrastructure to support a competitive supply chain and offer opportunities to add value.

- The early emergence of the hosting facilities at the Science Park as a 'meet me' point for carriers to bring connectivity, overcoming the problem of "where shall we meet?'

- The leadership role played by the city council and the universities, in creating awareness through projects like the Manchester Host, in the creating the first hosting facilities on the Science Park, and in the creation of MaNAP.

In the 1990s, the work of the technology and information society team within the city's Economic Initiatives Group continued to focus on developing a balance between traditional 'high-tech' (largely 'technology push') innovation and 'accessible tech' (largely 'demand stimulation') open innovation. In the latter case, it was again grass roots initiatives, such as those driven by the voluntary sector (NGOs), which were particularly innovative using digital technologies to develop networks of creatives, electronic arts initiatives and e-enabled community activities from the bottom up. The early digital business networks coalesced into the Manchester Digital trade association, launched in 2001, and largely survived the 'dot com' boom and bust, but there was a growing recognition by this time that accessibility to digital technologies had to be improved significantly if any competitive edge developed by the city was to be sustained. This meant not only improved networks and services for business but also for all local residents, especially those who, in spite of economic growth during the late 1990s, were still socially excluded, and for public sector services.

In 1996, the Manchester Telematics Partnership was launched as a local innovation networks, bringing together business, research, public bodies and community-based organisations, focusing on digital development. This was very much influenced by the continuing work that Manchester was doing with other European cities, which provided growing evidence of the need for more proactive approaches to investing in digital infrastructure and services. Firstly, through Telecities, of which it was a founder member and hosted the founding conference in 1993, and more widely through EUROCITIES where the late Councillor Brian Harrison, the first Chair of the City's Economic Development Committee in the 1980s, went on to be chair of the 
EUROCITIES Economic Development Committee (1996-1998). The experience of other bottom-up developments, such as the community-based digital networks and infrastructures in Amsterdam (through its Digital City project 'Digitale Stad' in 1994 and the Waag Society MediaLab), Barcelona (with the Barcelona Community Network), Bologna (with its citizens community network) and Stockholm (with its municipal fibre company-Stokab), convinced senior decision makers in Manchester to take a much wider look at this agenda and how it could benefit Manchester, building on the second great digital revolution, the coming of broadband and the 'always on' availability of the Internet and Web services.

Current debates at the time (late 1990s) tended to focus on the more optimistic view that e-services will be able to empower citizens and provide for their full participation in an emerging 'digital democracy', whilst there was concern that continuing inequalities, especially at a spatial level, were ignoring the realities of power which could be seen to support, what was called at the time, 'an information aristocracy', with elite access, rather than an effective 'digital democracy'. It was felt then that if there is not full accessibility to the new digital infrastructures and services for all citizens, then the outcome will simply reinforce existing patterns of inequalities with 'information haves' and 'have nots' in our communities. This is still seen as a real challenge to realising the idea of a 'Smart City' today. Manchester's experience during this period, i.e. from the mid-1990s to the mid-2000s, was that capacities and capabilities needed to be built up amongst local innovators, entrepreneurs and small businesses (SMEs) and that one important factor in achieving this was public investment in key enabling facilities such as Manchester Science Park and other local innovation incubators. This is a key reason why Manchester continues to balance 'top-down' strategic initiatives with 'bottom-up' grass roots development, through local user networks, such as the Manchester Digital Lab (MadLab; www. madlab.org).

\title{
Open Access in the Digital Economy: From the Legacy of the Commonwealth Games to Ambitions for Manchester in the Global Digital 'Premiership'
}

\author{
Innovation and Technology in Urban Regeneration: The Experience of East \\ Manchester
}

Manchester's work to date on technology and information society issues is based on the premise that urban regeneration is an essential prerequisite for tackling social exclusion and economic restructuring. Cities across the world face similar challenges in terms of finding coherent and effective policies and strategies that will enable them to deal with rapid industrial restructuring. They aim to support and sustain economic growth, connecting the opportunities created by economic growth with the needs of their citizens, in spite of the volatility of global markets, especially in terms of the current economic crisis. The emergence of the information society added new complexities to this process, on the one hand adding to the speed and scale of change whilst on the other hand providing new tools and processes which can be used in order to mitigate the impact of that change. 
Manchester has experienced new economic growth developing side by side with persistently high levels of unemployment, poverty and social exclusion. It has the fourth highest rate of multiple deprivation (apart from parts of Merseyside and London) and the highest rate of child poverty in the UK. This 'tale of two cities' syndrome (as it has been referred to) threatens to undermine the longer term sustainability of economic development and growth. It is in this context that Manchester's work on the information society and 'digital development' continued to be an important crosscutting theme within its City-Region Economic Development Strategy and Action Plans. The central aim is that digital technologies should be used to increase citizens' access to skills, jobs, and services and support greater participation in civic life, including in the regeneration process itself.

Manchester is the UK's second largest metropolitan area outside of London, with a population of over 2.5 million in the Greater Manchester City Region. At its core is the City of Manchester, the first industrial urban area in the world and the 'original, modern' city. Alongside the city's transformation from industrial to knowledge economy is the legacy of high levels of unemployment and poverty from the experience and impact of the economic restructuring of the 1970s and 1980s. Much of this legacy is concentrated in the traditional industrial manufacturing area of the city, in East Manchester; once home to more than 100,000, its population had declined significantly to less than 30,000 people by 2000 .

East Manchester was, and is, a regeneration challenge of regional and national significance [5]. An area of 1,100 ha situated immediately east of Manchester's City Centre, East Manchester presents an opportunity for regeneration on a scale and diversity almost unprecedented in an English city. There are unique opportunities for the renaissance of the area as a focus for the knowledge-driven economy of the twenty-first century. These opportunities have been generated by there being a range of regeneration initiatives focusing upon East Manchester to address many of the physical, economic and social problems in the area. These, in turn, build upon the stimulus provided by a buoyant economy within Manchester and the major investment attracted through the staging of the Commonwealth Games in 2002 and related legacy projects. The strong commitment by the government to the success of cities and to tackling the most acute areas of deprivation is also a key factor driving this impetus, as is the partnership working between generated between the local community and local and national government.

A major influence on Manchester's approach to digital development and, most recently, on work on the concept of the 'Smart City' is the experience gained in East Manchester where the City Council formed an Urban Regeneration Company, New East Manchester Ltd., a public-private-community partnership operating on a not-for-profit basis. An online community network, run in partnership with local citizens organisations and representatives, known as 'Eastserve', was established there in 2001. This was the location of the Commonwealth Games in 2002, which brought much needed investment and new facilities and resources in to the area, which had been the major industrial area of the city for more than 100 years until industrial restructuring brought factory closures, massive unemployment and environmental degradation over a 25-year period up to the late 1990s. 
Manchester First Living Lab Initiative-'Eastserve'

The 'Eastserve' initiative was one of a range of legacy projects where the investment attracted by the Commonwealth Games, including the City of Manchester Stadium (subsequently the home of Manchester City Football Club and now renamed as the Etihad Stadium), would continue to have positive impacts in supporting local residents to gain skills and access to employment, including through ICT projects. Even in 2001, many residents in the East Manchester area used cheap mobile phones rather than fixed telephone lines. The initial survey work undertaken by the area regeneration partnership (in 2001) revealed that more than $25 \%$ of homes no longer used landlines. This led to changes to the initial aims and objectives of the project which had been to provide PCs to households with dial-up Internet access. This meant that a system of wireless broadband connectivity was required which then enabled households to access the Internet and online services.

More than 2,000 of the area's homes were Internet-enabled through wireless broadband Internet connections, as well as 17 local schools, eight 'UKOnline' community access centres and 10 public access points in libraries and other centres. They all connected to a $100-\mathrm{Mbps}$ licensed wireless backbone linking four tower blocks around the East Manchester area from where bandwidth is distributed over a wireless network. Schools and public buildings receive an online community service, developed by Eastserve, and relay it to other residential locations. These locations are grouped in clusters and communicate with one another wirelessly via a radio dish antenna connected to a wireless bridge.

Underpinning this approach was the provision of micro-loans through the local Credit Union which enabled people to buy computer equipment, which, because they were paying for it, increased the 'value' that they put on this and enhanced their sense of ownership over the process and its results. Many of the people involved had never saved before or, in some cases, did not have bank accounts, so the project also had a positive impact on the Credit Union, increasing membership from a few hundred to some 2,000 people.

At the time, this was one of the largest community-based all-wireless broadband networks in Europe and the largest community regeneration initiative using digital technologies in the UK. In spite of being one of the poorest areas in the city, the takeup of broadband in the area is far higher than the citywide rate, and residents are using their new skills to improve their access to training and jobs. In one of several evaluation studies of the impact of the project, it was shown that Eastserve users are:

- More aware of job opportunities

- Want access to more training

- More likely to seek work

- More likely to take part in other educational opportunities

- More likely to be looking for new challenges

- More interested in running their own businesses

Over $40 \%$ of residents have now had basic ICT training because of EastServe, more than double the rate of most areas in the city, and $20 \%$ of these were moving on to extended courses which provide opportunities for accreditation, again more than double the rates for initiatives in other parts of the city. 
Learning the lessons from the work in East Manchester influenced thinking about how to extend this and develop similar initiatives in other parts of the city, around the idea of the Manchester Living Lab, and how to develop a citywide strategy for what was now termed 'digital development' with continuing support both to and from local grass roots initiatives.

\section{The Manchester Digital Strategy: From Local Digital Action to the Manchester Living Lab}

Digital Development Supporting Neighbourhood Regeneration As A Starting Point for a 'Smart City'

In 2002, Manchester hosted the world's second largest sporting and cultural event, the Commonwealth Games, and following this, there was a citywide review of all of the City Council's services and structures. One result of this was that the City Council decided to change the way it delivered its Economic Development Strategy, focusing future work in strategic initiatives in defined Area Regeneration Partnerships and in sector initiatives. This led to the Technology and Information Society Team in the Economic Initiatives Group becoming the core of the new MDDA (www. manchesterdda.com), set up as a city region-wide initiative in 2003 with the mission:

To make Manchester a leading world class digital city, having one of the most competitive broadband infrastructures in Europe, attracting and sustaining investment in ICT and e-commerce across all sectors of the economy, generating new businesses, developing new learning cultures, promoting social inclusion and providing all residents with the skills and aspirations to play a full role in the information society. [6]

In 2005, the Government published the UK Digital Strategy [7], which included proposals for a UK "Digital Challenge" where local authority-led partnerships would be invited to put in innovative proposals for accelerating digital development at a local level. The MDDA was responsible for coordinating a response to this, working in partnership with other public sector bodies, including the other municipalities in the city region, other public sector bodies, business and the voluntary and community sector. In January 2007, Manchester City Council submitted the Open Network EManchester (ONE-Manchester) Partnership Digital Challenge proposal [8] to the government with plans for developing "universal, affordable next generation broadband access" which "is essential to connect all residents and businesses of the Manchester City-region to the social, educational, informational and economic opportunities they deserve". This established the foundation for the creation of a Manchester Digital Strategy with a vision of creating the city region as "the most advanced 'next generation' connectivity in the UK, providing a sustainable base for high growth business, innovation, transformational public services and an inclusive knowledge society".

The thinking at that time was that Manchester, as the 'original, modern' city, faces many challenges in sustaining its economic growth and in connecting the opportunities created by this growth with the needs of local residents, maximising local benefit. 
Not least of these challenges is the way that ever-accelerating developments of digital technologies are creating what has been referred to as a digital 'paradigm shift' in the global economy. Various terms are being used to describe this - the 'Web 2.0' world, 'wikinomics' [9] and the new 'long tail' [10] economic world where millions of micro-businesses and e-traders create as much economic wealth and opportunity as the traditional large corporate companies. Another challenge for Manchester was how best to continue to balance the strategic priorities of the City Council with the ideas and demands coming from service users and the wider community, including SMEs generally and the digital and creative sectors specifically.

The ONE-Manchester Digital Challenge proposals aimed to capitalise on this and to set out a 'route map' for a third wave of development which would use the very latest digital technologies to support further economic growth, tackle the digital divide and create inclusive sustainability. This led to the development of Manchester first specific Digital Strategy [11], approved by the City Council in March 2008, with proposals for a 'Next-Generation Digital City' aiming to make Manchester a worldclass exemplar of how to lead this third wave around four main themes:

(a) Sustaining economic growth, especially through the digital/creative sector, new micro-businesses, digital social enterprises and creating e-traders

(b) Promoting digital inclusion, ensuring that all residents can access the online services, technologies and applications that they need

(c) Continuing to transform public services through innovative uses of digital technologies

(d) Promoting inclusive sustainability where digital technologies are used more innovatively to support sustainable energy communities, intelligent buildings, teleworking, improved mobility, telecare and a greater quality of life generally

\section{Digital Collaborations Through Living Labs: Networked City to Networking City}

The new Digital Strategy combined, firstly, continuing engagement and outreach work with innovation 'actors', both through new institutional networks, such as 'Manchester Knowledge Capital (M:KC)' [12], and through the networks of SMEs and community organisations, and, secondly, the lessons being learnt from experience in East Manchester. This provided the basis for a lot of new thinking and ideas which, in turn, enabled a new stage of digital development in the city.

This was happening at the same time as Manchester's work within EUROCITIES had brought it into contact with the network in Helsinki which was working with the MIT Media Lab [13] to develop the idea of Living Labs. ${ }^{1}$ During the 1990s,

\footnotetext{
${ }^{1}$ Living Labs grew out of an initiative in 2000, following the ideas of Bill Mitchell at MIT, by Nokia Research Labs, the VTT Finnish National Research Centre and Helsinki City Council to find new ways of trialling and testing ICT products and services through mass participation of users. The University of Salford had long been collaborative partners with VTT and invited Manchester City Council to join a new EU collaborative research project called 'Intelligent Cities' in 2001 which was subsequently funded by the EU's 6th Framework Programme (FP6). As a result of the project, a European Network of Living Labs (ENoLL; www.openlivinglabs.eu) was established in 2006, with the Manchester iving Lab as one of the first 20 members. There are now more than 200 Living Labs in the network.
} 
Manchester was successful in a number of EU-funded projects, coordinated through Telecities and EUROCITIES, including:

- The European Digital Cities project (FP4)

- The INFOCITIES project (TEN-Telecom)

- The Intelligent Cities ("IntelCities") project (FP6)

One of the consistent partners in much of this work was the City of Helsinki, and their partners from Nokia and VTT were also involved. Having seen and understood what they were doing with their Living Lab concept, i.e. getting research out of the research labs and into the hands of real people in local neighbourhoods, there were clearly a number of parallels with the work going on in East Manchester. As well as being a very good basis for knowledge exchange, these collaborations also convinced the Helsinki network to talk to their European partners, including Manchester, about launching a European Network of Living Labs. Manchester joined in with this at the beginning in 2005 and then became a founder member of the network when it launched in 2006.

The Living Labs 'movement' is driven by the idea of user-driven open innovation where users are involved at all stages of the innovation process, from design, implementation to application and service development. This brings some of the traditions and experiences of co-creation within software development, e.g. within the open-source community, into the wider world of new product and service development and delivery. This is a welcome development as, despite some encouraging trends with public awareness and use of user-generated content and social networking, the development of new services and applications remains dominated by the multinational corporate sector, leading to a pattern of 'development from above'. If the new infrastructures and applications are to benefit a much wider spectrum of public involvement than is currently the case, there is a need for civic commitment and public support, including financial resources, at all levels to support 'development from below' in applications and services, especially if the full potential of the 'Web 2.0' paradigm is to be realised. There is, then, a distinct 'applications gap' at the level of local citizens; too many of whom still sit on the wrong side of the 'digital divide'. The most effective way of bridging this gap is by stimulating greater engagement and experimentation, empowering users to develop digital literacy and competences for themselves, and to use these to create their own content and services.

The objective of such initiatives is to provide a wide range of insights which can be usefully drawn upon by others in developing alternative systems, geared to different local needs in different places. Local experimentation therefore becomes part of citywide and region-wide 'learning networks' whereby the insight gained in one environment can be transferred with suitable adjustments to another. If these 'learning networks' can then link up - nationally and internationally - then there is the basis for a potentially powerful counterbalance to vested interests, in terms of corporate and state interests, which can be much more proactive in taking an advocacy role in relation to consumer, citizen and wider democratic interests. Developments in advanced communications need to be accompanied by a strategy for development from below which seeks to realise the indigenous potential of cities and regions. Social innovation in the community-involving local government, schools and colleges, public libraries, the voluntary sector, consumer groups and 
trade unions - is a necessary counterpart to organisational innovation led by industry, commerce and government.

Both the idea and the practice of Living Labs, especially in the Manchester context, is then a very significant one, providing a mutually beneficial way of organising key parts of the innovation process and involving people locally, whether residents, students or businesses, in the co-creation and co-production of new applications and services. In Manchester, this meant that the MDDA effectively became the coordinating Living Lab for the city, both running some user-driven open innovation projects itself and also facilitating and supporting similar projects coming from grass roots initiatives with local research bodies, SMEs, artists and creative networks, and other community-based organisations.

\section{Towards 'Smart Cities': Engaging with the Future Internet and the Digital Agenda}

\section{Putting People at the Heart of the Digital Agenda: 'Smart Citizens in Smart Cities'}

The Manchester Digital Strategy provided the framework for the MDDA's work programme over the past 3 years (2008-2011) around the three core themes of digital inclusion, digital industries and digital innovation (as outlined previously). This includes taking forward key ideas outlined in the original 'ONE-Manchester' Digital Challenge proposal, such as 'turning the digital divide into a digital dividend'- the central theme of the proposal. This looked at the longer term sustainability of digital inclusion policies and practices by developing a new collaborative delivery mechanism for digitally enabled services and social networking.

The original idea was to provide a sustainable digital development model which could be used to create social capital and community cohesion, also aimed at creating a greater 'sense of place' within socially excluded communities through digital inclusion and capacity building. This, in turn, aims to support the transformational government agenda by providing services which are more accessible and more personalised through innovative uses of digital technologies. As this work develops, more attention is also being given to create new and more imaginative business models, especially building upon the experience of social enterprise development, including the idea of 'Digital Cooperatives', new social (economy) enterprises, which would coordinate and support local, regional and national initiatives and realise the benefits of a 'digital dividend'.

This work became central to discussions within the Living Labs network about how to engage with new ideas and approaches, particularly those coming out of the EU's Future Internet Research \& Experimentation (FIRE) community. There is a 'third wave' of Internet development underway, where the "Internet of things", i.e. networked objects, meets 'web-centric services', often referred to as the 'Internet of services/Internet of people'. The challenge is how these developments can be translated into practical initiatives that meet the wider goals of the Living Labs movement to co-create and co-produce new 'Future Internet'-enabled services that deliver a more inclusive and sustainable knowledge society. At a local level, the challenge is to harness these to deliver local benefit, promoting digital inclusion, helping the digital 
sector to grow and create skills and jobs that are accessible to local people and providing the required digital infrastructure to support innovation and future growth.

This is why the MDDA and its partners have been refining the vision originally outlined in the ONE-Manchester proposals and the Manchester Digital Strategy to focus on the concept of 'Smart Citizens in Smart Cities' using digital technologies to promote community engagement, capacity building and social capital. To use the four-level social capital model, this includes:

- Firstly, creating a common vision and a sense of belonging for all communities through imaginative uses of digital technologies to help to transform lives

- Secondly, ensuring that diversity is appreciated and positively rewarded through improved accessibility of digital technologies to support social networking

- Thirdly, engaging people from different backgrounds through the use of digital technologies which enables them to have similar life chances

- Fourthly, encouraging strong and positive relationships to be developed between people from different backgrounds in the workplace, in education and within neighbourhoods by using digital technologies to break down barriers and promote social cohesion

The MDDA's projects continue to combine innovation through new initiatives, including the Manchester Living Lab, so that it can be the way by which people and businesses can easily connect and collaborate with MDDA projects and other initiatives, together with the further development of well-established practice, especially in terms of digital inclusion, such as the 'Selling on the Web' courses.

The starting points for this are:

- Access: Ensuring that all local residents, plus those who come to Manchester to work, study or visit, have the most accessible and affordable ways to use the Internet open to them, including through local access centres, NGA networks and wireless connectivity

- Business opportunities: Enabling existing digital businesses to safeguard existing jobs and create new ones, developing pathways into employment through training and skills programmes, including apprenticeships, and generating new business opportunities by supporting new start-ups and social enterprises and promoting new trading opportunities and promotional activities, including through the Manchester Digital trade association and the annual 'Big Chip' awards

- Capacity building: Using digital technologies to build social capital and to support community engagement so that there is real local benefit generated by innovation which, in turn, increases digital inclusion, provides access to skills and jobs and improves the quality of life, including through 'green digital' and open data initiatives, working in collaboration with local partners such as the MadLab

Examples of MDDA project development in these areas include:

- 'Fibre to the People': The Manchester Living Lab pilot project which is starting in the Corridor area (around Oxford Road, Ardwick and Hulme wards and Knott Mill) to roll out next-generation access digital infrastructure using point-to-point, open-access fibre networks and advanced wireless connectivity 
- Manchester 'Internet Hub': Ensuring that Manchester can develop its 'Internet exchange' capacity to be a globally competitive 'Internet hub' based on enhancing connectivity across the city, especially between Manchester Science Park, Sharp and Media City UK

- Low Carbon Open Data Network - 'Lodanet': Extending the wireless connectivity around the Corridor area to collect real-time environmental data using lowcost, low-power sensing equipment and providing open access to the data through a range of online services

- Smart Innovation \& People_-SMARTiP_-'Smart Citizens in Smart Cities': A European project connecting up digitally supported community engagement initiatives in Manchester and four other European cities working in partnership with Peoples Voice Media's 'community reporters' project and the University of Manchester

- Green Digital Charter: A European-wide initiative to reduce the environmental impact of digital technologies and to develop innovative 'smart energy' projects, such as Internet-based interactive smart meters, that can improve energy efficiency and get people involved in new and imaginative ways of reducing their personal and collective carbon footprints

- Digital and Creative Skills: Bringing together businesses in the digital and creative sectors, including through Manchester Digital, education and training providers, community networks and other major employers to develop more innovatory ways for people to gain skills that can help them get access to jobs, set up their own businesses and get access to advanced learning opportunities through non-traditional routes, including apprenticeships

Creating A More Inclusive and Sustainable Approach to Digital Development in Manchester

Manchester's current digital projects aim to support the city region continuing to be the engine of regional growth. In order to remain competitive, however, Manchester believes that it needs to remain ahead of the curve in terms of digital access, infrastructure and services. This requires a proactive approach at a number of different levels:

(a) Early, affordable access to 'the next generation' of open-access fibre-based digital networks for business, public services and the wider community which are capable of delivering the support required for Future Internet-enabled services to generate economic growth. Bandwidth demand is increasing exponentially, which means that, given the lead times for infrastructure developments, cities need to be acting now.

(b) Increasing the capacity for innovation-especially as the digital and creative industries and the knowledge economy are so important to the UK economy. Cities are the places where these sectors cluster and, in so doing, create new ideas for products and services and high-value employment opportunities. Easy access to next-generation digital networks is a catalyst for cross-sector collaboration and experimentation. Our ambition is to turn Manchester into a digital test bed, an open innovation 'Living Lab' for Future Internet next-generation 
services and applications, whether ultrafast broadband, smart energy, e-health or new virtualised capacities through 'cloud computing'.

(c) Creating an enhanced ability to generate and share new ideas-NGA is not just about 'superfast' download speeds. In cities particularly, clusters of high-tech digital companies are involved in creating and sharing digital media content and in developing and owning their own infrastructure, so symmetric connectivity with fast upload speeds and open-access networks are equally as important as faster download speeds.

(d) Making digital greener and more sustainable: NGA is equally about new green infrastructures as cities are the primary producers of carbon emissions and, consequently, need to be using NGA to underpin the shift to a low-carbon economy by developing new and more sustainable ways in which people can work, study and live. Virtual business networks, for example, using applications such as 'telepresence' can deliver both carbon reductions and access to wider markets. Manchester's work on leading a European wide initiative in partnership with Eurocities to develop this theme around the 'Green Digital Charter' is another example.

(e) Developing more efficient public services - NGA is key to enabling city service providers to maximise the ability for citizens to self-serve and to provide efficient access to expensive specialist resources, such as expert medical care, using innovative new services such as telemedicine. A further benefit to cities could be the sharing of expertise and collective response to the market in digital networks and specialist services, including shared infrastructure around data hosting, disaster recovery and virtualisation, including cloud-based applications and services.

(f) Exchanging knowledge and expertise - cities are ideally placed to mobilise and aggregate demand for NGA services for the Future Internet 'Smart City' and to provide the strong leadership required to make this happen. The 'Core Cities' network is currently working on an initiative to develop closer engagement between city leaders, government, communications service providers and the Internet industry as a whole. In particular, Manchester is keen to continue working with other cities to influence government policy to recognise the national importance of investment in urban infrastructure to complement the rural 'last third' agenda. Consequently, we are establishing a forum within 'Core Cities' where this engagement can regularly take place and the emerging 'Smart Cities' agenda can be shaped through city leadership and regional networking.

A transformational digital infrastructure for the region will require three components:

- Access networks: Serving businesses and citizens that will take us through the next 20 years and that will offer the maximum opportunity for local businesses to play a role in the supply chain. This effectively means 'fibre to the premises' (FTTP) networks supported by the latest wireless technologies. These fibre networks need to be fully open - shared by competing providers and not dominated by any one company or technology.

- Digital hubs: Where these networks connect with each other and with the rest of the internet, where digital businesses can host the new applications and services 
on servers connected to these networks, and sometimes where the businesses themselves can locate. These hubs will play a similar role to Internet Exchanges (of which Manchester has the only significant one outside London in the UK), but more of them will be needed, closer to the end users.

- Backbone networks: Connecting these hubs to each other and with the internet exchange in Manchester. These networks also need to be fully open, available to technology companies and service providers to adapt with different technologies and to compete with each other. This is the primary role of the proposed NGA deployment in the Manchester City Region.

By bringing low-cost, open-access connectivity to several important regional centres, starting with the Manchester City Region, such a network can effectively spread the benefit of the South Manchester Internet Exchange (currently clustered around Manchester Science Park) to other parts of the region. This would dramatically improve the business case for the development of hubs and access networks in these areas - initially creating a city region-wide digital development zone in Manchester and then systematically extending this to other NGA projects across the region.

Truly transformational digital infrastructure requires the widest possible availability and accessibility of fully open-access FTTP networks and the digital hubs to support them. Greater acknowledgement needs to be given to the active debate which is going on about the extent of market failure in urban areas as well as rural areas, especially that much more needs to be done beyond simply aggregating/stimulating demand. Active intervention is required on the basis of opening up the building, management and development of fully open-access NGA networks using new and innovative business models, including the potential for social enterprises and dynamic forms of public-private-community partnerships. This should include reuse of public assets, as is being developed in Manchester in partnership with Metrolink (the tram network) and Transport for Greater Manchester, and innovation through improved collaboration between higher and further education, the private sector and local authorities to develop the transformational digital infrastructure of the future.

The Manchester City Region currently has very little of this kind of capacity in terms of the global scale of development, but plenty of potential. It has its small Internet Exchange, is developing the pilot NGA access network in the Corridor 'Living Lab' project (extending links into the Internet Exchange), and it has a new putative hub in The Sharp Project (to the north of the city centre). Competitor cities like Amsterdam are pushing fast to develop this type of infrastructure at a massive scale through initiatives such as the rapid expansion of the Amsterdam Internet Exchange, 'AMSIX', now the largest in the world, and through gigabit trials on its 'City Net' fibre network. Given new opportunities, such as the expansion of the Metrolink tram network, however, Manchester now has a unique opportunity to gain ground and become a global competitor in this field.

Developing NGA infrastructure through the Metrolink-based tramside network by itself does not provide all three components of the infrastructure that are needed, but it does bring two key benefits:

- It underpins their development by providing a kick start to one crucial component - the backbone infrastructure to connect hubs and access networks to each other and to the rest of the Internet. 
- It provides an immediate and affordable infrastructure that can be used by private and public sector to interconnect important centres. Contrary to popular belief, 'dark fibre' connectivity is scarce and hoarded by its owners to provide more lucrative leased active services.

This then would act as the catalyst for further investment, and there are a number of ways in which the public sector could see further economic and social benefits from this approach:

- Public sector agencies joining a consortium that invests in and utilises the network could save very substantial costs on connectivity to the Internet and also some point-to-point routes. Improvements in connectivity will enable efficiencies in service delivery.

- This approach would bring high-speed, high-quality and affordable business connectivity to parts of the city region that would otherwise miss out. This would stimulate investment leading to increased employment with consequent direct and indirect returns for the public sector.

- By enabling the creation of new, affordable access networks in communities that would otherwise miss out, this could lead to creating new pathways to employment and skills, supporting, in turn, increased social inclusion, better education and job prospects, reduced crime and other indirect benefits.

Towards a Manchester Roadmap for Creating Future Internet-Enabled Services in Smart Cities

The Manchester City Region NGA initiatives are being developed in partnership by the MDDA, which is part of Manchester City Council, and the Commission for the New Economy, working on behalf of the Association of Greater Manchester Authorities in the context of the City Region Pilot and the proposed 'Combined Authority'. There are currently three linked initiatives being developed:

(a) The Corridor 'Living Lab' NGA pilot project, aiming to connect 500 businesses and 1,000 residential users through a FTTP network, being built by Geo on behalf of the Corridor Partnership, coordinated by Manchester City Council through the MDDA. This will be an access network test bed enabling new business-to-business, business-to-consumer and community-based applications and services to be developed as well as innovation in public service delivery in areas such as telecare/e-health, energy efficiency/smart energy, e-learning, smart mobility and flexible working. This is currently being built, and the Living Lab test bed will start trialling applications, including advanced wireless linked to fibre networks, from the end of 2011 for an initial period of 18 months.

(b) The Manchester 'Virtual Internet Exchange' proposal which aims to connect the Corridor fibre network along Metrolink to Manchester two other key economic growth areas: Central Park, which includes the Sharp Project, and then to other key sites, initially in East Manchester.

(c) The Manchester City Region NGA Initiative which is currently undertaking a feasibility study on the scope for market investment in new and innovative models of NGA delivery which would harness the advantages of the core 
network being developed in Manchester and extend this using all possible routes, e.g. Metrolink and other transport corridors together with Public Service Network development, across the whole of Greater Manchester, including those in the 'final third' rural communities and those in inner urban excluded from access by virtue of financial and other social barriers.

The challenge now is to identify how best to link these proposals in with national policy objectives and to seek support to accelerate their implementation. The Manchester City Region partners believe that this is an innovative approach which, whilst initially is very much related to the specific opportunities offered because of Manchester's local experience and economic culture, can provide knowledge and experience which would be of benefit to all local areas and regions, urban and rural, in developing NGA across the UK.

This underpins the work that MDDA is doing to develop the scale and scope of the Manchester Living Lab through projects which deliver local benefit around the core themes of its work programme. Drawing upon its experience as a partner in the EU (FP7-funded) Future Internet Research \& Experimentation By Adopting Living Labs (FIREBALL; www.fireball4smartcities.eu), project Manchester has developed its new Green Paper (referred to previously, in "Innovation in Regeneration: A Proactive Approach to Economic and Social Change" above) with a 'Roadmap' for the Local Digital Agenda in Manchester. This aims to translate the overall 'Roadmap' for Smart Cities developed through the FIREBALL project [14] into a specific document focused on the needs and strategic objectives of a specific city, in this case Manchester.

This covers not only existing projects being undertaken by city through the MDDA but also 'bottom-up' grass roots initiatives being developed by local partners in collaboration with the MDDA. The 'Roadmap' aims to map existing work going on in the city region, which is relevant to the 'Smart Cities' agenda, and to identify how this fits into the future vision, the challenges and gaps which exist, and the future solutions and innovation needs in terms of realising the targets and aspirations of the Manchester City Region. The 'Roadmap' is seen as a first stage in the process of developing the Local Digital Agenda for Manchester, and the Green Paper is in place to stimulate discussion and consultations so that these responses can be used to validate proposals for future work and that this will be able to inform the production and implementation of the Local Digital Agenda for Manchester.

The Green Paper also sets out what are seen as the real challenges for realising the 'Smart Cities' vision in Manchester, particularly in terms of creating:

active citizen engagement in the planning, development and delivery of future Internet-enabled services in ways which are accessible, empowering and sustainable. There is certainly a much wider appreciation of why this is being suggested or, in some cases, demanded, but this has not yet been matched by action at any widespread or systematic level. This is why Manchester is committed to the three step approach outlined below:

- Firstly, identifying and analysing good practice, e.g. 'OpenApps' development, 'Apps4' places (such as http://www.verkkodemokratia.fi/apps4finland and http:// www.gov20.de/apps-4-berlin/), which are felt to be relevant and (potentially) transferrable to pilot projects being developed at a local level; 
- Secondly, acting as a catalyst to generate new pilot projects that build on existing good practice at a local level but which also embrace new developments from across Europe and globally which are identified through supporting networks, such as EUROCITIES and the European Network of Living Labs (ENoLL);

- Thirdly, drawing out the lessons learned to identify how best to use and reuse the results from pilot projects, both in terms of enhancing the scope and scale at a local level, through extending their reach and developing new business models applicable locally, and in terms of wider replicability across Europe. [15]

\section{Conclusions: Manchester as a Future Internet-Enabled 'Smart City'}

The experience gained in Manchester through the delivery of local projects over the past 5 years has enabled a reevaluation and refocusing of digital development priorities around ideas of citizen engagement and 'smart citizens' needing to be at the centre of Manchester's proposed 'Local Digital Agenda'. The aim is to create a virtuous circle whereby:

(a) Digital inclusion generates skills and aspirations across all sections of society and reengages people in all aspects of civic life, and;

b) Digital industries generate new employment opportunities and pathways into these through skill development with local people and the institutions that support this, particularly schools and colleges, and;

(c) Digital innovation is the engine of this growth, with new next-generation openaccess digital infrastructures and services, such as smart energy and smart health/wellbeing, underpinning this and enabling more sustainable growth whilst supporting greater community engagement which, in turn, supports digital inclusion, especially through Manchester Living Lab initiatives.

The key to realising this, as a 'Smart City' strategy for the city region, is to sustain the momentum of work done to date through:

- City leadership (continuing support from the main decision makers at the highest level)

- Investment in new digital infrastructures and services (even in spite of the economic crisis, where new and more innovative approaches and business models will be needed more than ever)

- Exemplar projects and activities which really stimulate interest and engagement (two examples in Manchester currently would be the Manchester Digital Lab, MadLab and the Future Everything Festival)

The Future Internet-enabled 'Smart City' is about the transformation of urban living through the imaginative use of digital technologies and ensuring that this can make a significant contribution to sustainable economic growth both immediately and in the longer term. At the same time, these technologies also provide opportunities to transform the lives of local residents and the neighbourhoods where they live. This is why the focus on tackling the digital divide and promoting digital inclusion is continuing to be seen as a priority, highlighting the need to ensure that citizens have 
the capacity, skills and motivation to take advantage of these technologies and that there is a real commitment to focus not only on the transformation of public services in terms of 'business process' but also on co-production, the direct and active engagement of users in the design, delivery and, where needed, the ownership of services.

Some of the policies, as outlined above, are in place to facilitate and support the transformation process of Manchester into a 'Smart City', but there is still much to be done to ensure that the opportunities that the Future Internet can provide to a city region such as Manchester are fully exploited.

There are a number of specific lessons that can be learnt from Manchester's experience which will be used to inform future strategies and the proposed Local Digital Agenda for Manchester in particular:

- The need to develop digitally enabled services that are based on the social, cultural and economic needs of the neighbourhoods, requiring a combination of detailed local research and real efforts to consult with and engage local people as an essential prerequisite for capturing user needs and involving users in the design and delivery of new services, the start of the co-production process

- That the stakeholders in the project, especially the public sector, need to demonstrate a long-term commitment to community engagement and capacity building and invest as much in the development of people's skills, confidence and aspirations as in the technology being deployed

- The need to have an ongoing evaluation strategy that not only has the ability to identify weaknesses, and even failures, but also has the role of communicating these results directly into the strategic decision-making process so that the project can adapt and evolve as quickly and effectively as possible, backed up by effective project management resources

- The importance of developing real exemplars that push the boundaries of what people know and their expectations so that people's imaginations are stimulated and horizons widened and that this is communicated with all the power that Future Internet-enabled communications can bring, making use of all the capabilities that the most effective social media and social networking can offer

- The potential for generating added value from innovation and new investment into the area whilst at the same time focusing existing investment within those locations and sectors which are most capable of delivering growth in order to respond to the ongoing structural shifts in the economy towards knowledge industries, including Future Internet-enabled services, particularly as this is accelerated by economic crisis

This then is the basis for the next stage of this work in Manchester:

(a) Using the Green Paper to focus on the issue of 'Smart Cities - Creating an Inclusive and Sustainable Knowledge Society' to stimulate further interest and engagement about the concept through consultation and linkages with grass roots initiatives

(b) Developing the new strategy as 'A Local Digital Agenda for Manchester' to support future work, coordinated by the MDDA and the Manchester Living Lab initiative with stakeholders and partners from across the city region 
(c) Continuing to build the trans-European 'Smart Cities Network' to exchange experience and expertise on how to translate the concept of the 'Smart City' into reality, working with networks including EUROCITIES and the European Network of Living Labs and securing resources through EU collaborative projects

\section{References}

1. Marketing Manchester (2009) Original, modern. Marketing Manchester publications. http://issuu.com/ manchestermagazine/docs/original_modern?viewMode=presentation\&mode=embed

2. European Commission (2010) A digital agenda for Europe. COM (2010) 245 final/2

3. Komninos N, Schaffers Hans, Pallot M (2011) Developing a policy roadmap for smart cities and the future Internet. In: Cunningham P, Cunningham M (eds) eChallenges e-2011 Conference Proceedings

4. Fensom $S$ (2011) Internet hub. Unpublished paper

5. Grant L (2010) Reclaiming East Manchester. NEM

6. Manchester City Council (2003) Report on establishing the Manchester Digital Development Agency (MDDA). MCC

7. HM Government (UK) (2005) Connecting the UK: the digital strategy. Prime Minister's Strategy Unit Joint Report with Department of Trade and Industry (DTI)

8. Manchester City Council (2007) ONE-Manchester Partnership Digital Challenge Proposal. MCC

9. Tapscott D, Williams A (2006) Wikinomics. Atlantic Books, London

10. Anderson C (2006) The long tail. RH Business Books, London

11. Manchester City Council (2008) Manchester Digital Strategy. MCC

12. Manchester City Council (2003) Manchester: knowledge capital. MCC

13. Mitchell W (1999) e-topia: urban life, Jim — but not as we know it. MIT Press, Cambridge

14. FIREBALL Project (2011) D3.2 Smart city roadmap (Interim Report). MCC

15. Manchester City Council (2011) Green Paper: Smart Cities-Creating an Inclusive and Sustainable Knowledge Society: A Local Digital Agenda for Manchester (Consultation Draft). MCC 